\title{
Over Torsiyonuna Genel Bakış
}

\author{
Overview of Ovarian Torsion \\ Fazilet Kübra BOYNUKALIN', Süleyman GÜVEN² ${ }^{2}$ Emine Seda GÜVEN ${ }^{3}$, Mehtap POLAT ${ }^{1}$
}

\author{
${ }^{1}$ Anatolia Tüp Bebek Merkezi, Kadın Hastalıkları ve Doğum Kliniği, Ankara \\ ${ }^{2}$ Karadeniz Üniversitesi Farabi Hastanesi, Kadın Hastalıkları ve Doğum Kliniği, Trabzon \\ ${ }^{3}$ Rize Eğitim Araştırma Hastanesi, Kadın Hastalıkları ve Doğum Kliniği, Rize
}

\begin{abstract}
öz
Over torsiyonu nadir görülen ancak ciddi sonuçlara yol açabilecek jinekolojik acillerden biridir. Over torsiyonu tanısı her zaman kolay olmamaktadır. Gri skala ultrasonografi (USG) her ne kadar over torsiyonu için özgün bulgular ortaya koymasa da ilk başvurulan görüntüleme yöntemidir. Doppler USG ile kan akımının gösterilmiş olması over torsiyonu tanısını ekarte ettirmese de, kan akımınının belirlenmemesi tanıyı destekleyici bulgulardandır. Cerrahi öncesi over torsiyonu tanısında güvenilirliği ve duyarlılığı yüksek serum belirteci henüz tanımlanmamıştır. Hızlı tanı ve cerrahi tedavi, hastanın fertilitesinin; overinin korunmasının temelidir. Bu derlemenin amacı over torsiyonu konusunda genel değerlendirme yapmaktır.
\end{abstract}

Anahtar Kelimeler: Over torsiyonu, IL-6, iskemi modifiye albumin, D-dimer, IL-8, USG, doppler USG.

\begin{abstract}
Torsion of the ovary is rare but serious cause of gynecologic emergency. Diagnosis of ovarian torsion (OT) is difficult. Ultrasonography has no specific finding for diagnosis of OT, it is initial imaging technique. Presence of vascular flow detected by doppler USG doesn't exclude diagnosis of OT but, absence of vascular flow is suspicious for diagnosis. The main challenge about diagnosis is that many of patients undergo surgery without confirmed diagnosis while rapid clinical workup and surgical treatment are keys to preserve fertility. Specific biomarkers supporting diagnosis of OT aren't currently available. Aim of article is to make an overview of OT.
\end{abstract}

Keywords: Ovarian torsion, IL-6, ischemia modified albumin, D-dimer, IL-8, USG, Doppler USG. 


\section{Giriş̧}

Acil servise başvuran ve yapılan fiziki muayenede akut karın bulguları saptanan kadınlarda, her yaş grubu için ayırıcı tanıda over torsiyonu düşünülmelidir. Ancak kesin tanıyı koymak, over torsiyonunun belirtilerinin özgün olmaması nedeniyle her zaman çok kolay olmamaktadır. Doğru ve erken tanı koymak, özellikle genç yaştaki hastalarda overin kurtarılması ve ilerleyen yıllarda fertilitenin korunması açısından önemlidir (1). Ayrıca tanıdaki gecikmeler, çok nadir olarak tromboflebite ve ciddi peritonite yol açabilir (2).

\section{OVER TORSIYONU NEDIR VE KIMLERDE NE SIKLIKLA GÖRÜLÜR?}

Overin destek aldığı ligamentlerin etrafında dönmesi ile ortaya çıkan over torsiyonu her yaş grubunda karşılaşılabilecek jinekolojik acil bir durumdur. Bazı olgularda, overle birlikte komşu tüpün de kendi etrafında döndüğü saptanabilmektedir ve bu durum adneksial torsiyon olarak adlandırılmaktadır. Overin destek ligamentleri; utero-ovarian ligament, broad ligament ve broad ligamentin bir katlantısı olan ve overe ait vasküler yapıların yer aldığı infundibulopelvik ligamenttir. İnfundibulopelvik ligamentin kendi etrafında dönmesi sonucu arterial, venöz ve lenfatik akım engellenir. Engellenen venöz ve lenfatik akım sonucu overde ödem gelişir ve geliş̧en ödem zaten azalmış olan arterial akım üzerine daha da azaltır. Arterial akımdaki azalma iskemiye yol açar ve iskemi sonucu nekroz, infarkt ve lokal hemoraji oluşur. Nekroza giden over dokusu fonksiyonunu kaybeder ve zaman içerisinde involüsyona uğrar.

Erişkinlerde, over torsiyonu görülen vakaların $\%$ 50-80'inde fonksiyonel kist ya da neoplastik kist ile karşılaşılmaktadır $(2,3)$. Herhangi bir patolojik yapı olmadan da over torsiyonu gözlenebilmektedir; genellikle premenarş grubunda görülen over torsiyonu normal over dokusunda gözlenir. Over torsiyonu genellikle sağ overde gözlenir. Bu durum; sağ infundibulopelvik ligamentin daha uzun olmasına bağlı olarak overin kendi etrafında dönme olasılığının artması ile açıklanmaktadır. Ayrica solda yer alan sigmoid kolonun over için bir destek teşkil etmesi nedeniyle torsiyon olasılığını düşürdüğü düşünülmektedir (4).

Kesin olarak prevalansı bilinmese de over torsiyonunun cerrahi gerektiren jinekolojik acillerin \%2.7'sini oluşturduğu, geçmiş yıllarda yapılan bir çalışmada belirlenmiştir (5). Amerikan Pediyatri Cemiyeti 2010 yılında yapmış oldukları bir değerlendirmede 1-20 yaş arasındaki çocuklarda over torsiyonu insidansını 4.9/100000 olarak değerlendirmişler ve \%58'inin ooferektomi ile tedavi gerekliliği olduğunu saptamışlardır (6). Ancak, bazı torsiyon olgularına cerrahi uygulanmamış olması nedeniyle gerçek prevalansın çalışmalarda belirlenenden daha fazla olduğu düşünülmektedir (7).

Over torsiyonu için risk faktörleri; üreme çağında olmak, 5 cm'den büyük over benign ya da malign over kitlesine sahip olmak, gebelik, ovulasyon indüksiyonu, daha önceden over torsiyonu geçirmiş olmak olarak sıralanabilir (7). Malign tümörlerde ve endometrioma olgularında komşu organlarla yapışıklığa sıkça rastlandığı için adneksial torsiyon daha nadir olarak gözlenmektedir (8). Gebelikte adneksiyal torsiyonun özellikle ilk trimesterde arttığı belirlenmiştir ve etyoloji korpus luteum kistine bağlanmıştır (9). Ovarian stimulasyon sırasında artan over ağırlığı ve hacmi over torsiyonunu predispose eden faktör olarak karşımıza çıkmaktadır (10).

\section{OVER TORSIYONUNUN KLINIK TABLOSU NASILDIR?}

Kliniktablo hastaların büyük bir kısmında, akut başlayan ciddi pelvik ağrı ile kendini gösterir. Houry ve ark, retrospektif olarak 15 yıllık sürede cerrahi olarak over torsiyonu tanısı kesinleşmiş hastaların acil servise başvurularında ağrılarının karakteristik özelliklerini analiz etmiştir (11). Olguların \%59'u ani başlayan karın ağrısı tariflemiştir, \%70'i ağrı keskin ve bıçak saplanır tarzda olduğunu ifade etmiştir. Olguların \%50'si ağrının kramp tarzında olgunu belirtmişlerdir.

Fiziki muayene akut karın bulguları ve ele gelen adneksial kitle açısından dikkatli olarak yapılmalıdır. Ateş ve lökositoz diğer saptanabilecek bulgular arasında yer alır. Klinik 
tablogözönüne alındığında ayırıcı tanıda erişkin hastalar için ektopik gebelik, pelvik inflamatuar hastalık, appendisit, divertikülit, hemorajik over kisti ve renal kolik yer almaktadır. Pediyatrik yaş grubunda benzer klinik tablo ile karşımıza çıksa da neonatal dönemde bulgular genellikle karın distansiyonu, bulantı, kusma, huzursuzluk ve irritabilite ile kendini gösterir (12).

\section{OVER TORSIYONU ŞÜPHESI OLAN HASTALAR NASIL DEĞERLENDIRILIMELIDIR?}

Over torsiyonu şüphesi olan hastaların değerlendirilmesinde öncelikli olarak detaylı bir hikaye alınmalıdır. Ağrının ne zaman başladığı, eşlik eden bulantı kusma ve ateş gibi bulguların olup oladığı detaylı olarak gözden geçirilmelidir. Alınan hikayede, daha önceden saptanmış herhangi bir over kistinin varlığı, ovülasyon indüksiyonu yapılıp yapılmadığı sorgulanmalıdır.

Yapılan fizik muayenede, karın bölgesinde hassasiyet, rebound ve defans bulgularının varlığı var ise hangi bölgeye lokalize olduğu belirlenmelidir. Ayrıca Fizik muayenede ele gelen herhangi bir adneksiyal kitle olup olmadığı muhakkak değerlendirilmelidir. Yine Houry ve ark yapmış oldukları değerlendirmede olguların \%47'sinde ele gelen kitle tespit edildiğini belirtmişlerdir. Ayrıca olguların \%29'unda akut karın bulgularına rastlanmadığı saptanmıştır (11).

Karın ağrısı şikayeti ile başvuran yetişkin hastalarda doğru tanı koyabilmek için yapılması gereken değerlendirmelerin başında $\beta$-hCG, hematokrit, beyaz küre sayımı gelmektedir. $\beta$-hCG, ektopik gebelik ayırıcı tanısının yapılmasında etkindir. Hematokrit değerlendirilmesi ile hemorajik kist rüptürü değerlendirilmesi yapılabilmektedir. Beyaz küre sayımında sıkça lökositoza rastlanmasına rağmen lökositoz ile doku nekrozu arasında herhangi bir ilişkiye rastlanmamıştır (13).

Tüm bu değerlendirmelere rağmen gerek hikaye, gerekse fizik muayene bulgusu olarak over torsiyonuna özgü herhangi bir bulgu belirlenmemiştir. Özellikle üreme çağındaki kadınlarda akut karın ayırıcı tanısı yapılırken over torsiyonu akılda tutulmalıdır.

\section{OVER TORSIYONUNUN TANISINDA KULLANILAN GÖRÜNTÜLEME YÖNTEMLERI NELERDIR?}

Gerek abdominal yolla yapılan, gerekse transvajinal yol kullanılanılarak yapılan gri skala ultrasonografi (USG) over torsiyonu şüphesi olan olgularda ilk başvurulacak görüntüleme yöntemidir. Over torsiyonunu destekleyen USG bulguları; büyümüş over dokusu, overde kistik ya da solid kitle belirlenmesi, over stromasında heterojen görünüm, çok sayıda küçük peripheral folikül görülmesi (over dokusunda gelişen ödeme bağlı olarak), over lokalizasyonunun değişmesi ve over dokusunun etrafında ve Douglas boşluğunda serbest sıvı varlığı olarak sıralabilir $(14,15)$. USG ile yapılan değerlendirme sonrasında yukarıda bahsedilen bulguların hepsi ile karşılaşılabileceği gibi sadece bir tanesi ile de karşılaşılabilir; nadir de olsa hiçbir tanesi saptanamayabilir.

Doppler USG, over torsiyonu tanısı için başvurulan görüntüleme yöntemlerinden bir tanesidir. Bilindiği gibi over dokusu çift yönlü kan akımına sahiptir. Torsiyon olgularında öncelikli olarak etkilenen venöz akımdır, daha sonra arterialakımbozulur. BunedenleDopplerUSGile kan akımının belirlenmiş olması over torsiyonu olasılığını ortadan kaldırmaz. Literatürdeki yayınlar incelendiğinde over torsiyonu olguları ile yapılan değerlendirmelerde Doppler USG ile anormal kan akımı paterni gözlenmesi olguların \%35-95'inde saptanmıştır. Doppler USG'nin duyarlılığının veözgüllüğünün değerlendirildiği çalışmalarda saptanan farklı rakamlar bu durumdan kaynaklanmaktadır. Ayrıca akım paterninin değerlendirilmesinde kantitatif testler değil kalitatif testlerin kullanılması da önemli bir etkendir. Bütün bunların yanı sıra, kan akımının paterni, obstrüksiyonun şiddetine göre değişmektedir (16). Karın ağrısı şikayet ile başvuran ve adneksiyal kitle saptanan 199 hastanın prospektif olarak değerlendirildiği bir çalışmada Doppler USG ile venöz akımın saptanmaması veya bozulmuş saptanmasının over torsiyonu tanısında \%100 sensitivite ve \%97 spesifiteye sahip olduğu belirlenmiştir (17). 
Huchon ve ark, yapmış oldukları retrospektif bir çalışmada bir oluşturmuşlar ve oluşturdukları bir modelin over torsiyonu tanısındaki güvenilirliğini belirlemişlerdir. Karın ağrısı, ilk başvurudan sonra ağrının 8 saatten daha kısa sürmesi, kusma, USG ile overde 5 cm'den büyük kist tespit edilmesi ve lökore ya da anormal vajinal kanama olmaması değerlendirilen beş parametre olarak belirlenmiştir ve bu modelin güvenilirliğinin \%75 olduğu belirlenmiştir (18). Magnetik rezonans (MR) ve bilgisayarlı tomografi (BT), adneksiyal kitlenin belirlenmesinde ve iskemi bulgularının ortaya konulmasında yardımcı olmasına rağmen over torsiyonun tanısında USG değerlendirilmesine fazladan katkısı olmamaktadır. Ayrıca MR ve BT kullanımı maliyeti arttırabilir ve zaman kaybına neden olabilir (19). Wilkinson ve arklarının yapmış oldukları çalışmada over torsiyonunda görüntüleme yöntemlerinin bulguları detaylı olarak değerlendirilmiş ve şu sonuca varılmıştır; her ne kadar USG over torsiyonu şüphesi olan hastalarda ilk başvurulan yöntemse de, pek çok hastaya $B T$ ve $M R$ uygulanmaktadır. BT ve MR'da özgün bulgular olmasa da büyük over veya eşlik eden over kisti ya da solid yapı belirlenebilir. Aynı zamanda USG'de olduğu gibi BT ve MR'da overin malrotasyonu belirlebilir (20).

\section{OVER TORSIYONU TANISINDA SERUM BELIRTEÇLERININ YERI VAR MIDIR?}

Günümüzde, over torsiyonuna tanı koymak için kullanılan günlük pratiğimize girmiş hızlı ve özgün sonuç veren bir laboratuar testi henüz yoktur. Ancak, günlük pratikte yeri olabilecek pek çok serum belirtecinin over torsiyonunun tanısındaki yeri araştırılmaktadır. Ayrıca, yapılan hayvan deneyleri ile over torsiyonunda henüz günlük pratiğimizde yeri olmayan serum belirteçlerinin değerlendirilmesi yapılmıştır.

Cohen ve ark. 'ın yapmış oldukları çalışmada kalp krizi geçirmiş hastalarda ve diğer iskemi durumlarında akut faz reaktanı olarak arttığı belirlenmiş olan interlökin 6 (IL-6) ve tumor nekroz faktörü a (TNF-a) düzeylerinin over torsiyonu olgularında belirleyici olup olmadığı değerlendirilmiştir. Bu çalışmada acil servise başvuran 20-45 yaş arasında, karın ağrısı şikayeti olan ve akut karın bulguları saptanan, USG'de over kisti belirlenen olgular değerlendirilmiştir. Gebelik testi pozitif olan, ağrının nedeninin başka patolojilere bağlandığı olgular (akut apandisit, idrar yolu enfeksiyonu) çalışmaya dahil edilmemiştir. Over torsiyonu ön tanısı ile laparoskopi yapılan 20 hastanın 8'inde tanı işlem sonrası doğrulanmıştır. Yapılan değerlendirmede over torsiyonu saptanan 8 olgunun 6'sında IL-6 düzeyi yüksek saptanmıştır. Buna karşın torsiyon belirlenmeyen 12 olgunun hiçbirinde IL-6 düzeyi yüksek saptanmamıştır. İstatistiksel değerlendirmede aradaki fark anlamlı bulunmuştur. TNF-a düzeyleri ise torsiyonu olan 8 hastadan 2'sinde torsiyon saptanmayan 12 hastanın 4'ünde yüksek bulunmuştur. İstatistiksel değerlendirmede aradaki fark anlamlı bulunmamıştır. IL-6 düzeyininovertorsiyonutanısınınkonulmasında spesifik bir test olabileceği belirlenmiştir (21).

2006 yılında yapılan başka bir çalışmada over torsiyonu tanısı konmasında IL-6, IL-8 ve E-selektin düzeylerinin yeri olup olmadığı değerlendirilmiştir. Çalışmaya akut başlayan karın ağrısı şikayeti ile başvuran ve $5 \mathrm{~cm}$ 'den büyük over kitlesi bulunan ve diğer patolojilerin ekarte edildiği, over torsiyonu ön tanısı ile cerrahiye alınmış 50 olgu dahil edilmiştir. 50 olgunun sadece 13'ünde tanı cerrahi olarak doğrulanmıştır. Torsiyon saptanan ve saptanmayan gruplar değerlendirildiğinde sadece IL-6 düzeyi anlamlı olarak torsiyon saptanan grupta yüksek bulunmuştur. IL-8, TNF-a ve E-selektin düzeyleri arasında her iki grup arasında fark saptanmamıştır (22).

2011 yılında yapılan bir çalışmada 6-21 yaş arası alt kadran ağrısı ile başvuran bayanlarda cerrahi gerektiren ve gerektirmeyen olgularda CD64 ve IL-6 düzeyleri değerlendirilmiştir. Cerrahi gerektiren olgular appendisit ve over torsiyonu olarak belirlenmiştir. Cerrahi gerektiren olgularda IL-6 düzeyi belirgin olarak yüksek belirlenmiştir (23).

IL-6'nın over torsiyonu tanısının konulmasındaki yeri ile ilgili yapılan bir meta-analizde karın ağrısı ile gelen ve USG'de over kisti saptanan hastalarda IL-6 düzeyinin saptanmasının over 
torsiyonu tanısı konulmasında duyarlılığının \%85.7 olduğu saptanmıştır (24).

Aranvearkyapmışolduklarıhayvançalışmasında over torsiyonunda iskemi modifiye albumin (IMA) düzeylerini belirlemiştir. Sıçanlarda yapılan bu çalışmada torsiyon olgularında IMA düzeyi anlamlı olarak daha yüksek çıkmıştır. Aynı zamanda sıçanlarda torsiyon öncesi ve sonrası yapılan IMA değerlendirilmesinde IMA'nın belirgin olarak daha yüksek olduğu saptanmıştır (25). IMA insanlarda iskeminin tespitinde kullanılabilecek olan spesifik olmayan belirteçlerden bir tanesidir. Pulmoner emboli, mezenterik iskemi ve kalp krizinde IMA düzeylerinin yükseldiği belirlenmiştir (26). IMA değerlendirmesinin en büyük avantajı kolay uygulanabilir bir yöntem olmasının yanı sıra, günümüzdeki mevcut ticari kitler sayesinde 12 dakika gibi kısa bir sürede sonuç alınabiliyor olmasıdır. Ancak insanda over torsiyonu tanısında IMA düzeylerini değerlendiren klinik bir çalışma bulunmamaktadır.

D-dimer değerlendirilmesi, yıllardır venöz tromboemboli tanısı için yardımcı olarak kullanılmaktadır. Kart ve ark yapmış oldukları hayvan çalışmasında torsiyon olgularında D-dimer düzeyleri değerlendirilmiştir. D-dimer düzeyleri torsiyon olgularında yüksek olarak belirlenmiştir (27). D-dimer insanlarda, başta venöz tromboemboli olmak üzere pek çok durumun tanısında kullanılmasına rağmen düşük spesifiteye sahiptir. Gerek insanda torsiyon olgularında D-dimer düzeylerini değerlendiren çalışma olmaması gerekse testin spesifitesinin düşük olması nedeniyle günümüzde rutin kullanımı yoktur.

Gelişen radyolojik tekniklere rağmen, over torsiyonu tanısı jinekolojik aciller içerisinde en çok zorluk çekilenidir. Erken tanı ve acil tedavi, over fonksiyonunun korunması için çok önemlidir. Bu nedenle, hızlı sonuç veren spesifik serum belirteçleri, önem arz eder. Ancak günümüzde henüz rutin kullanıma geçmiş herhangi bir serum belirteci bulunmamaktadır.

\section{OVER TORSIYONU TEDAVISI NASIL OLMALIDIR?}

Günümüzde over torsiyonunun gerek tanısının kesinleştirilmesinde gerekse tedavisinde kullanılan yöntem laparoskopi ya da laparotomidir. Cohen ve ark 2003 yılında yaptıkları çalışmada cerrahi olarak tedavi edilmiş 102 olguyu değerlendirmişlerdir. Laparaskopi ile tedavi edilen 65 hasta ile, laparotomi ile tedavi edilen 35 hasta retrospektif olarak değerlendirildiğinde over fonksiyonu ve tromboemboli riski açısından herhangi bir fark saptanmamıştır (28). Hastanede kalış süresinin daha kısa olması ve operasyon sonrası ağrının daha az olması nedeniyle eğer ekipman sıkıntısı yaşanmıyorsa tercih edilecek yöntem laparoskopidir.

Geçmişte overin detorsiyonu sonrası olası emboliye riski nedeniyle olgularının tamamında ooferektomi yapılırken, bu görüş günümüzde tamamiyle terk edilmiştir (29). Torsiyon olgularında, detorsiyone edildikten sonra overin renginde düzelme olmazsa ooferektomi yapılması gerekteği terk edilmiş görüşler arasındadır. Oelser ve arkadaşlarının yapmış oldukları çalışmada 102 over torsiyonu olgusu değerlendirilmiştir. Tüm olgular detorsiyone edilerek tedavi edilmiştir. Detorsiyon sonrasında halen nekrotik olmasına rağmen ooferektomi uygulanmayan olgularda IVF tedavisi sırasında foliküler gelişim saptanmış ve oosit elde edilebilmiştir (30).

Torsiyon olgularının çok büyük bir kısmında yer alan over kistlerine müdahele edilmesi önerilmemektedir. Torsiyon olgularında görülen kistlerin büyük bir kısmının fonksiyonel kist olduğu belirlenmiştir. Torsiyon nedeniyle ödemli olan over dokusundan kistektomi yapılırken daha fazla zarar verileceğinden endişe edilmektedir (30).

\section{KAYNAKLAR}

1. Bayer Al, Wiskind AK. Adnexal torsion: can the adnexa be saved. Am J Obstet Gynecol 1994;171(16):1506-11.

2. Nichols DH, Julian PJ. Torsion of the adnexa. Clin Obstet Gynecol 1985;282(2):375-80.

3. Warner MA, Fleischer AC, Edell $S L$, et al. Uterine adnexal torsion: sonographic findings. Radiology 1985; 154(3):773-5.

4. Pena JE, Ufberg D, Cooney N, Denis AL. Usefulness of doppler sonography in the diagnosis of ovarian torsion. Fertil Steril 2000;73(5):1047-50. 
5. Hibbard LT. Adnexal torsion. Am J Obstet Gynecol 1985;152(4):456-61.

6. Guthrie BD, Adler MD, Powell EC. Incidence and trends of pediatric ovarian torsion hospitalizations in the United States, 2000-2006. Pediatrics 2010;125(3):532-8.

7. Huchon C, Fauconnier A. Adnexal torsion: a literature review. Eur J Obstet Gynecol Reprod Biol 2010;150(1):812.

8. Sommerville M, Grimes DA, Koonings PP, Campbell K. Ovarian neoplasms and the risk of adnexal torsion. Am J Obstet Gynecol 1991;164(2):577-8.

9. Kumari I, Kaur S, Mohan H, Huria A. Adnexal masses in pregnancy: a 5-year review. Aust N Z J Obstet Gynaecol 2006;46(1):52-4.

10. Mashiach S, Bider D, Moran O, Goldenberg M, BenRafael Z. Adnexal torsion of hyperstimulated ovaries in pregnancies after gonadotropin therapy. Fertil Steril 1990;53(1):76-80.

11. Houry D, Abbott JT. Ovarian torsion: a fifteen-year review. Ann Emerg Med 2001;38(2):156-9.

12. Rousseau V, Massicot R, Darwish AA, et al. Emergency management and conservative surgery of ovarian torsion in children: a report of 40 cases. J Pediatr Adolesc Gynecol 2008;21(4):201.

13. Oelsner G, Shashar D. Adnexal torsion. Clin Obstet Gynecol 2006;49(3):459-63.

14. Albayram F, Hamper UM. Ovarian and adnexal torsion: spectrum of sonographic findings with pathologic correlation. J Ultrasound Med 2001;20(10):1083-9.

15. Vijayaraghavan SB. Sonographic whirlpool sign in ovarian torsion. J Ultrasound Med 2004;23(12):1643-9.

16. Duigenan S, Oliva E, Lee SI. Ovarian torsion: diagnostic features on $\mathrm{CT}$ and $\mathrm{MRI}$ with pathologic correlation. Am J Roentgenol 2012;198(2):122-31.

17. Nizar K, Deutsch M, Filmer S, et al. Doppler studies of the ovarian venous blood flow in the diagnosis of adnexal torsion. J Clin Ultrasound 2009;37(8):436-9.

18. Huchon C, Staraci S, Fauconnier A. Adnexal torsion: a predictive score for pre-operative diagnosis. Hum Reprod 2010;25(9):2276-80.

19. Chiou SY, Lev-Toaff AS, Masuda E, Feld Rl, Bergin D. Adnexal torsion: new clinical and imaging observations by sonography, computed tomography, and magnetic resonance imaging. J Ultrasound Med 2007;26(10):1289_ 301.
20. Wilkinson C, Sanderson A. Adnexal torsion -a multimodality imaging review. Clin Radiol 2012;67(5):47683

21. Cohen SB, Wattiez A, Stockheim $D$, et al. The accuracy of serum interleukin- 6 and tumour necrosis factor as markers for ovarian torsion. Hum Reprod 2001;16(10):2195-7.

22. Daponte A, Pournaras S, Hadjichristodoulou C, et al. Novel serum inflammatory markers in patients with adnexal mass who had surgery for ovarian torsion. Fertil Steril 2006;85(5):1469-72.

23. Reed JL, Strait RT, Kachelmeyer AM, Byczkowski TL, Ho ML, Huppert JS. Biomarkers to distinguish surgical etiologies in females with lower quadrant abdominal pain. Acad Emerg Med 2011;18(7):686-91

24. Christopoulos G, Goubet S, Kelly T. Interleukin-6 for the diagnosis of ovarian torsion: a systematic review and meta-analysis. J Obstet Gynaecol 2013;33(5):438-41.

25. Aran T, Guven S, Unsal MA, Alver A, Mentese A, Yulug E. Serum ischemia-modified albumin as a novel marker of ovarian torsion: an experimental study. Eur J Obstet Gynecol Reprod Biol 2010;150(1):72-5.

26. Lippi G, Montagnana M, Guidi GC. Albumin cobalt binding and ischemia modified albumin generation: an endogenous response to ischemia? Int J Cardiol 2006;108(3):410-1.

27. Kart C, Aran T, Guven S, Karahan SC, Yulug E. Acute increase in plasma D-dimer level in ovarian torsion: an experimental study. Hum Reprod 2011;26(3):564-8.

28. Cohen SB, Wattiez A, Seidman DS, et al. Laparoscopy versus laparotomy for detorsion and sparing of twisted ischemic adnexa. JSLS 2003;7(4):295-9.

29. McGovern PG, Noah $R$, Koenigsberg R, Little AB. Adnexal torsion and pulmonary embolism: case report and review of the literature. Obstet Gynecol Surv 1999;54(9):601-8.

30. Oelsner G, Cohen SB, Soriano D, et al. Minimal surgery for the twisted ischae- mic adnexa can preserve ovarian function. Hum Reprod 2003;18[12]:2599-602. 